\title{
An Investigation of Oxygen Reduction Mechanism in Nano-sized LSCF-SDC Composite Cathodes
}

\author{
Hongmei $\mathrm{Xu}^{\mathrm{a}, \mathrm{b}} *$, Hua Zhang ${ }^{\mathrm{c}}$, Aimin $\mathrm{Chu}^{\mathrm{a}, \mathrm{b}}$ \\ ${ }^{\mathrm{a} C}$ College of Materials Science and Engineering, Hunan University of Science and Technology, Xiangtan, Hunan \\ 411201, China
}

${ }^{\mathrm{b}}$ Key Laboratory of High Temperature Wear Resistant Materials Preparation Technology of Hunan Province, Hunan University of Science and Technology, Xiangtan, Hunan 411201, China

${ }^{c}$ College of Mechanical and Electrical Engineering, Hunan University of Science and Technology, Xiangtan, Hunan 411201, China

Abstract: The $\mathrm{La}_{0.6} \mathrm{Sr}_{0.4} \mathrm{Co}_{0.8} \mathrm{Fe}_{0.2} \mathrm{O}_{3-}(\mathrm{LSCF})-\mathrm{Ce}_{0.8} \mathrm{Sm}_{0.2} \mathrm{O}_{1.9}(\mathrm{SDC})$ composite cathode for solid oxide fuel cells (SOFCs) based on SDC electrolyte, followed by being calcined at 1073K, 1173K, $1273 \mathrm{~K}, 1373 \mathrm{~K}$ and $1473 \mathrm{~K}$, was prepared by infiltration of LSCF precursor solution into porous SDC scaffolds. The average LSCF particle size is about $50 \mathrm{~nm}, 0.1 \mu \mathrm{m}, 0.15 \mu \mathrm{m}, 0.2 \mu \mathrm{m}$ and $1.2 \mu \mathrm{m}$ respectively after being calcined at $1073 \mathrm{~K}, 1173 \mathrm{~K}, 1273 \mathrm{~K}, 1373 \mathrm{~K}$ and $1473 \mathrm{~K}$ for $4 \mathrm{~h}$. The oxygen reduction reaction mechanism in the porous LSCF-SDC nano-sized composite cathode is studied through a comparison with that in the porous LSCF-SDC micro-size composite cathode. The oxygen reduction reaction mechanism in the LSCF-SDC composite cathodes is discussed in terms of frequency response, electrode resistance and reaction order at different oxygen partial pressures $p\left(\mathrm{O}_{2}\right)$. Three elementary steps are considered to be involved in the cathode reaction: ( $\mathrm{i}$ ) Dissociation of molecular adsorbed oxygen into atom adsorbed oxygen on cathode surface; (ii) Bulk diffusion of adsorbed of $\mathrm{O}^{2-}$ in the bulk LSCF phase; (iii) Oxygen ions transfer at the

*Corresponding author. Tel.:+86-0731-58290544; fax: +86-0731-58290544;

E-mail addresses:zh7xhm@sina.com 
interface between the cathode and the electrolyte. For the cathodes sintered at $1073 \mathrm{~K}$ and $1173 \mathrm{~K}$, the polar resistance in the medium frequency range was dominant and step ( ii) is the rate-determining step. The low frequency arc became obvious in the impedance spectra with increasing the calcination temperature of the LSCF precursors. The ratio of the polar resistance in the medium frequency range to the total cathode polar resistance decreases with increasing the calcination temperature, from $70.6 \%$ at $1073 \mathrm{~K}$ to $29.6 \%$ at $1473 \mathrm{~K}$, but the ratio of the polar resistance in the low frequency range to the total cathode polar resistance increases with increasing the calcination temperature, from $4.9 \%$ at $1073 \mathrm{~K}$ to $58 \%$ at $1473 \mathrm{~K}$, implying that the cathode process is limited by step (iii) when the cathode calcination temperature is at $1473 \mathrm{~K}$.

Key words: SOFC; Infiltration; Cathode; Nano-structure; oxygen reduction

\section{Introduction}

Solid oxide fuel cells (SOFC) have attracted much attention because of the high-energy conversion efficiency and environmental friendship [1], and are expected to become one of the major sources of power during this century. In recent years, one of the major targets for the development of SOFCs is a reduction in the operation temperature from $1273 \mathrm{~K}$ to below $1073 \mathrm{~K}$. A reduction of the operation temperature will allow broad choice of the electrode and interconnecting materials and reduce the system costs and increase the performance durability $[2,3]$. For the reduction of the operation temperature, the electrolyte ohmic resistance and the electrode polarization reaction resistance must be as small as possible. The electrolyte ohmic resistance can be reduced by reducing the conventional $\mathrm{Y}_{2} \mathrm{O}_{3}$ stabilized $\mathrm{ZrO}_{2}$ (YSZ) electrolyte thickness and/or utilizing ionic conductors superior to the YSZ, such as doped $\mathrm{CeO}_{2}$ 
and $\mathrm{LaGaO}_{3}$. However, the electrode polarization resistances (especially for the oxygen reduction reaction at the cathode), show relatively large values when the cell temperature is reduced [4,5]. Therefore, development of novel cathode materials and/or microstructure with superior electrocatalytic activity and long-term stability are critically important to achieve high enough power density at reduced temperature.

In recent years, numerous cobalt-based perovskite materials like $(\mathrm{La}, \mathrm{Sr})(\mathrm{Co}, \mathrm{Fe}) \mathrm{O}_{3-\delta}[6], \quad \mathrm{GdBaCo}_{2} \mathrm{O}_{5+\delta}[7], \quad \mathrm{GdBaCoFeO}_{5+\delta}[8], \quad \mathrm{Sr}_{1-\mathrm{x}} \mathrm{Ce}_{\mathrm{x}} \mathrm{CoO}_{3-\delta}[9]$, $\mathrm{Ba}_{0.5} \mathrm{Sr}_{0.5} \mathrm{Co}_{0.8} \mathrm{Fe}_{0.2} \mathrm{O}_{3-\delta}[10], \quad \mathrm{YBaCo}_{2} \mathrm{O}_{5+\delta}[11], \quad$ and $\quad \mathrm{Sm}_{\mathrm{x}} \mathrm{Sr}_{1-\mathrm{x}} \mathrm{CoO}_{3-\delta}[12]$ mixed ionic-electronic conductors (MIEC) have been paid great attention because they usually exhibited excellent electrochemical performance at intermediate-to-low temperature SOFCs. But the large thermal expansion coefficient, chemical instability with electrolyte materials and high temperature volatility prevent them from practical application. The nano-scale or nano-structure electrode by infiltration method attracts increasing attention as the viable alternative for the development of new electrodes for SOFCs. Infiltration method is a two-step sintering process, which effectively separate the catalytic active phase formation temperature from the sintering temperature as required to establish the intimate electrode/electrolyte interface bonding in the standard SOFCs electrodes. Due to the relatively low temperature for the formation of catalytic active phases, nano-size particles can be formed on the surface of the scaffolds, such as YSZ or doped $\mathrm{CeO}_{2}$ and $\mathrm{LaGaO}_{3}$, and the reaction between the catalytic active phases and the scaffolds can be avoided[13,14].

Despite a large amount of work aimed at characterizing the oxygen-reduction 
reaction in various nano-scaled composite cathodes, there is still much that is not known and debate about the reaction or how to promote it [15-17]. An understanding of difference in the cathode reaction mechanisms between conventional cathodes and nano-scale cathodes is needed. In this work, the oxygen reduction reaction in a nano-scaled $\mathrm{La}_{0.6} \mathrm{Sr}_{0.4} \mathrm{Co}_{0.8} \mathrm{Fe}_{0.2} \mathrm{O}_{3-\delta}(\mathrm{LSCF})-\mathrm{Ce}_{0.8} \mathrm{Sm}_{0.2} \mathrm{O}_{1.9}(\mathrm{SDC})$ composite cathode is investigated in terms of micro-structure, impedance spectra and the oxygen partial pressure $\left(p\left(\mathrm{O}_{2}\right)\right)$ dependence. The reaction mechanism of the LSCF-SDC composite cathode with larger grain size was also researched. It is expected that the research results can assist with the design of high-performance cathodes for SOFCs.

\section{Experimental}

\subsection{Electrolyte preparation}

SDC powders were synthesized by a sol-gel low temperature combustion synthesis method. Analytical-grade $\mathrm{Ce}\left(\mathrm{NO}_{3}\right)_{3} \cdot 6 \mathrm{H}_{2} \mathrm{O}, \mathrm{Sm}_{2} \mathrm{O}_{3}$, ammonium hydroxide and Citric acid were used as raw materials. Firstly, $\mathrm{Sm}_{2} \mathrm{O}_{3}$ was dissolved in warm diluted nitric acid (approximately 333K), then mixed with $\mathrm{Ce}\left(\mathrm{NO}_{3}\right)_{3} \cdot 6 \mathrm{H}_{2} \mathrm{O}$ according to the required molar ratio in a minimum volume of de-ionized water to obtain transparent aqueous solution. Proper amount of $\mathrm{NH}_{4} \mathrm{NO}_{3}$ was added as combustion aids. Citric acid was added in a proportion of 1.5 per mol metal ionic, and the $\mathrm{pH}$ value of the solution was adjusted to $\mathrm{pH}=6 \sim 8$ by adding ammonium hydroxide. The obtained translucent solution was evaporated at $353 \mathrm{~K}$ to remove the excessive water until it turned into a viscous gel. The viscous gel was ignited at $673 \mathrm{~K}$ in a pre-heated 
muffle furnace until it was completely burnt out to form loose powders. Pellets with about $13 \mathrm{~mm}$ in diameter and $1 \mathrm{~mm}$ in thickness were prepared by uniaxially pressing SDC powders at 200MPa.

\subsection{Symmetric cell construction}

Electrochemical properties of nano-scaled LSCF oxides as the active cathode catalysts were evaluated using symmetrical cathode fuel cells, which were based upon tri-layer structures of porous $\mid$ dense $\mid$ porous SDC that were prepared by spin coating SDC slurry onto both sides of a green pellet for dense SDC electrolyte. The SDC slurry was prepared by milling SDC powders, Ethyl cellulose ethoce and Alpha-Terpineol for $5 \mathrm{~h}$. The coated porous SDC was dried at room temperature for $24 \mathrm{~h}$ and subsequently fired at $1723 \mathrm{~K}$ for $4 \mathrm{~h}$ in air. The thickness of the porous layer was about $75 \mu \mathrm{m}$.

LSCF was introduced into the porous SDC scaffolds by infiltration with an aqueous solution consisting of $\mathrm{La}\left(\mathrm{NO}_{3}\right)_{3} \cdot 6 \mathrm{H}_{2} \mathrm{O}, \mathrm{Sr}\left(\mathrm{NO}_{3}\right)_{2}, \mathrm{Co}\left(\mathrm{NO}_{3}\right)_{2} \cdot 6 \mathrm{H}_{2} \mathrm{O}$ and $\mathrm{Fe}\left(\mathrm{NO}_{3}\right)_{3} \cdot 9 \mathrm{H}_{2} \mathrm{O}$ at a molar ratio of $\mathrm{La}: \mathrm{Sr}: \mathrm{Co}: \mathrm{Fe}=0.6: 0.4: 0.8: 0.2$. Citric acid, with a molar ratio of $1.5: 1$ to the metal cations, was used as a complexing agent in order to assist the formation of the perovskite phase at lower temperature. Ammonia was added to the above solution to adjust the $\mathrm{pH}$ value at $\approx 7$ in order to ensure full chelation of citric acid with metal ions. The precursor solution was subsequently heated on a hot plate until a molar concentration of $0.25 \mathrm{~mol} \cdot \mathrm{L}^{-1}$ was obtained. Infiltration steps were followed by $0.5 \mathrm{~h}$ heat-treatment at $873 \mathrm{~K}$ to decompose the nitrates. This procedure was repeated until a needed loading was achieved. The 
composite cathodes were then calcined to $1073 \mathrm{~K} \sim 1473 \mathrm{~K}$ for $4 \mathrm{~h}$.

\subsection{Microstructure characterizations}

The phase compositions of the impregnated LSCF-SDC composite cathodes were examined using X-ray diffraction (XRD, Bruker D8, Cu- $\left.\mathrm{K}_{\alpha}\right)$. XRD patterns were collected at room temperature with a step size of $0.02^{\circ}$ in $2 \theta$ over the scanning range of $10 \sim 80^{\circ}$. The microstructure of the LSCF-SDC composite cathodes was examined using the field emission scanning electron microscope (FESM-4800).

\subsection{Electrochemical measurement}

A four-probe method was used to measure the electrochemical impedance spectra of the symmetric cells. Measurements were taken over a temperature range of $673 \mathrm{~K} \sim 873 \mathrm{~K}$ and at oxygen partial pressures ranging from $10^{-2}$ to $1 \mathrm{~atm}$. Different oxygen partial pressures were realized by pre-mixing $\mathrm{O}_{2}-\mathrm{N}_{2}$ gas. The measurement was performed using an IM6 Electrochemical Workstation (Zahner, Germany) with a frequency ranged from $0.1 \mathrm{~Hz}$ to $1 \mathrm{MHz}$ and with an amplitude of $20 \mathrm{mV}$. Zivew software was used to fit the impedance data to obtain equivalent circuits.

\section{Results and discussion}

Fig.1 presents the SEM cross-sectional morphology of the tri-layer structures of porous $\mid$ dense $\mid$ porous SDC at $1723 \mathrm{~K}$ for $4 \mathrm{~h}$. The electrolyte layer is dense and the cathode skeleton is porous. The electrolyte has good bonding with the cathode backbone, which ensures to achieve high effective conduction of oxygen ion at the interface between the cathode and the electrolyte. The room temperature XRD pattern 
of the impregnated LSCF-SDC composite is shown in Fig.2, for a sample heated at 1073K for $4 \mathrm{~h}$. The LSCF perovskite and SDC structure were identified, and other impurity phases were not detected. This indicates that the formation of LSCF perovskite phase from the impregnated solution precursor can be completed at $1073 \mathrm{~K}$.

Fig.3 shows the SEM cross-sectional images of the impregnated LSCF-SDC composite cathodes calcinated at 1073K, 1173K, 1273K, 1373K and 1473K, respectively. The LSCF is present as discrete particles following calcinations at $1073 \mathrm{~K}$ for $4 \mathrm{~h}$, and the average size of the LSCF particles was about $50 \mathrm{~nm}$. The regions in the image without fine particles correspond to the SDC fracture surfaces. Upon being heated to higher temperature, the LSCF particles agglomerate and the particle-size distribution shifts toward larger particle size. By 1373K, the perovskite covers the underlying SDC skeleton completely in the form of dense film. The mean grain size is about $200 \mathrm{~nm}$. The mean grain size is larger, such as about $1.2 \mu \mathrm{m}$, when the LSCF precursor was heated to $1473 \mathrm{~K}$, and the micrograph of the porous LSCF-SDC composite cathodes is similar to that of the empty SDC scaffold (Fig.1).

Fig.4 indicates the impedance spectrum for the symmetric cell that its composite cathodes were calcined at $1073 \mathrm{~K}$ for $4 \mathrm{~h}$. The measurement was conducted at $873 \mathrm{~K}$ in atmospheric pressure $\left(p\left(\mathrm{O}_{2}\right)=0.21 \mathrm{~atm}\right)$ and the impedance has been divided by two to account for the presence of two symmetric cathodes. The intercept on the real axis at high frequency corresponds to the grain resistance of the electrolyte $\left(\mathrm{R}_{\mathrm{g}}\right)$ and the chord of the high frequency semi-circle corresponds to the grain boundary resistance $\left(\mathrm{R}_{\mathrm{gb}}\right)$ of the electrolyte. The corresponding conductivity of the electrolyte 
was $1.32 \times 10^{-2} \mathrm{~S} \cdot \mathrm{cm}^{-1}$, and very close to $1.36 \times 10^{-2} \mathrm{~S} \cdot \mathrm{cm}^{-1}$ for SDC at $873 \mathrm{~K}[18]$. The chord of the low frequency arc corresponds to the polar resistance $\left(R_{p}\right)$ of the cathode and the cathode process takes on a depressed arc. In order to better analysis the oxygen reduction reaction mechanism in the cathodes, the ohmic losses from the electrolytes were subtracted from the Cole-Cole plots in the next impedance spectra plots.

Fig.5 presents the impedance spectra of the LSCF-SDC composite cathodes sintered at different temperature. The measurement is conducted at $873 \mathrm{~K}$ in air. Significant increase of the cathode polarization resistance is clearly seen as a result of increasing the calcination temperature. The polar resistance of the composite cathode calcined at $1073 \mathrm{~K}$ was $0.21 \Omega \mathrm{cm}^{2}$. The polar resistance of the composite cathode calcined at $1173 \mathrm{~K}, 1273 \mathrm{~K}, 1373 \mathrm{~K}$, and $1473 \mathrm{~K}$ was $0.48 \Omega \bullet \mathrm{cm}^{2}, 1.02 \Omega \bullet \mathrm{cm}^{2}$, $1.6 \Omega \cdot \mathrm{cm}^{2}$ and $2.1 \Omega \cdot \mathrm{cm}^{2}$, respectively. The results indicate that the cathode electrochemical properties are very sensitive to sintering conditions.

To explain the drastic increase of the cathode polarization resistance due to increasing the calcination temperature of the LSCF precursor, it is necessary to understand the cathode reaction kinetics and the dominating step of the oxygen reduction reaction in the cathodes. The variation in impedance spectra of LSCF-SDC composite cathodes with respect to $p\left(\mathrm{O}_{2}\right)$ is presented in Fig.6. The oxygen partial pressure, $p\left(\mathrm{O}_{2}\right)$, is $0.01 \sim 1$ atm and the operating temperature is $773 \mathrm{~K}$. The impedance spectra provide the key information for the analysis of the oxygen reduction reaction in the cathodes. The resistance in the frequency range of $1 \mathrm{KHz} 100 \mathrm{~Hz}$ is 
independent of $p\left(\mathrm{O}_{2}\right)$. A change in the resistance related to the frequency range of $100 \mathrm{~Hz} \sim 1 \mathrm{~Hz}$ is not also apparent. But, a change in the resistance related to the frequency range below $1 \mathrm{~Hz}$ clearly change as the value of $p\left(\mathrm{O}_{2}\right)$ increases. Based on the above analysis, the impedance spectra of the LSCF-SDC composite cathodes at different $p\left(\mathrm{O}_{2}\right)$ were analyzed by fitting impedance data using Zview software. The equivalent circuit is inserted in Fig.7. $\left(\mathrm{R}_{\mathrm{H}} \mathrm{Q}_{\mathrm{H}}\right)$, $\left(\mathrm{R}_{\mathrm{M}} \mathrm{Q}_{\mathrm{M}}\right)$ and $\left(\mathrm{R}_{\mathrm{L}} \mathrm{Q}_{\mathrm{L}}\right)$ represent the high-frequency arc, intermediate-frequency arc and low-frequency arc, respectively, where $\mathrm{R}$ is the resistance of the corresponding arc, and Q is a constant phase element representing time-dependent capacitive effects. Fig7 is the impedance spectrum of the LSCF-SDC composite cathode calined at $1073 \mathrm{~K}$ at 0.01 atm $p\left(\mathrm{O}_{2}\right)$, and the operation temperature is $773 \mathrm{~K}$.

Oxygen reduction in the mixed ionic and electronic conductors ( MIECs ) can be divided into several elemental steps[19-21]: (1) Adsorption of $\mathrm{O}_{2}$ onto the MIECs surface; (2) Dissociation of absorbed $\mathrm{O}_{2}$ into oxygen atom on the MIECs surface with charge transfer and oxygen incorporation at the MIECs surface; (3) Surface diffusion of adsorbed oxygen on the MIECs surface; (4) Bulk diffusion of adsorbed of $\mathrm{O}^{2-}$ in the bulk MIECs phase; (5) $\mathrm{O}^{2-}$ transfer at the interface between the MIECs and the electrolyte; (6) Charge transfer and incorporation of adsorbed oxygen at the three phase boundary (TPB). The oxygen reduction reaction velocity can be determined by anyone of these elemental steps. However, the nested RC equivalent circuit has limitation due to its low distinguishability with respect to $p\left(\mathrm{O}_{2}\right)$. Therefore, we cannot simply and directly assign the single element of equivalent 
circuit to distinct physical process [22].

The relation between the specific electrode conductivity $\left(\sigma_{i}\right)$ and oxygen partial pressure $\left(p_{\mathrm{O}_{2}}\right)$ can be given by Eq.(1):

$$
\sigma_{i} \propto p_{O_{2}}^{n}
$$

Here, $n$ stands for the reaction order.

Table 1 shows the dependence $(n)$ of the conductivity $\left(\sigma_{i}\right)$ in different frequency range on the $p\left(\mathrm{O}_{2}\right)$. For all the symmetrical cells, the electrode resistance in the high frequency range is independent of $p\left(\mathrm{O}_{2}\right)$ and the reaction order $n$ shows very low values from 0.01 to 0.06 . The weak $p\left(\mathrm{O}_{2}\right)$ dependence of the high frequency resistance suggests that neither atomic oxygen nor molecular oxygen is involved in this reaction step. Therefore, the high-frequency arc could be interpreted as oxygen ion transfer from the cathode to the electrolyte[19,20, 23,24]. The $n$ value in the medium frequency range is about 0.25 . The medium-low frequency arcs are considered as the convoluted contribution of bulk diffusion of adsorbed of $\mathrm{O}^{2-}$ in the bulk LSCF phase[19-21]. In the low frequency range, the polar resistance exhibited a much stronger dependence on $p\left(\mathrm{O}_{2}\right)$, and the $n$ value was about equal to 0.5 . While the low frequency electrode processes are often considered to be associated with $\mathrm{O}_{2}$ bulk diffusion in the cathodes, the cathode is thin in this paper and the bulk diffusion can be explored. So the low frequency processes were associated with dissociative adsorption of molecular $\mathrm{O}_{2}$ on the LSCF surface[25,26]. The total cathode polar resistances for the LSCF-SDC composite cathode calcinated at different temperature, $R_{T}$, exhibited different $p\left(\mathrm{O}_{2}\right)$ dependence and the $n$ values increase with increasing the 
calcination temperature. The $\mathrm{n}$ value is about 0.25 when the calcination temperature is $1073 \mathrm{~K}$ or $1173 \mathrm{~K}$, but the $\mathrm{n}$ value is between 0.25 and 0.5 when the calcination temperature is above $1173 \mathrm{~K}$. The $n$ value was 0.42 and more close to 0.5 when the calcination temperature is $1473 \mathrm{~K}$. The results showed that $\mathrm{O}_{2}$ reduction reactions in the cathodes were dominated by different reaction step when the cathodes were calcined at different temperature. $\mathrm{R}_{\mathrm{H}}, \mathrm{R}_{\mathrm{M}}$ and $\mathrm{R}_{\mathrm{L}}$ of the LSCF-SDC composite cathodes calcined at different temperature are shown in Fig.8. All of $R_{H}, R_{M}$ and $R_{L}$ increase with increasing the calcinations temperature. The ratio of $R_{M}$ to $R_{T}$ decreases with increasing the calcination temperature, from $70.6 \%$ at $1073 \mathrm{~K}$ to $29.6 \%$ at $1473 \mathrm{~K}$, but the ratio of $R_{L}$ to $R_{T}$ increases with increasing the calcination temperature, from $4.9 \%$ at $1073 \mathrm{~K}$ to $58 \%$ at $1473 \mathrm{~K}$, implying that the cathode processes are limited by the medium frequency processes when the cathode calcination temperature is at $1073 \mathrm{~K}$ or $1173 \mathrm{~K}$, but the low frequency processes are obvious when the calcination temperature of the LSCF precursors are increased. The cathode processes were limited by the low frequency processes when the cathode calcination temperature is $1473 \mathrm{~K}$.

When the LSCF precursors were calcined at $1073 \mathrm{~K}$ for $4 \mathrm{~h}$, the LSCF coating is porous and the coating thickness is about $100 \mathrm{~nm}$. The average LSCF particle size is only 50nm. Compare with the conventional micro-sized composite cathodes, the specific surface area and the grain boundary area of the LSCF phase and the length of the three phase boundaries of the LSCF-SDC composite cathodes were increased, which were beneficial to the oxygen ions transfer in the LSCF bulk and from the 
cathode to the electrolyte and the dissociation of an adsorbed oxygen molecule. Upon heating to higher temperature, the LSCF particles agglomerate and the particle-size distribution shifts toward larger particle sizes. By $1373 \mathrm{~K}$, the perovskite covers the underlying SDC skeleton completely in the form of dense film, which will lead to the decrease of the specific surface area and the grain boundary area of the LSCF phase and the length of the three phase boundaries of the LSCF-SDC composite cathodes. All of $R_{H}, R_{M}$ and $R_{L}$ increase and $R_{L}$ increases faster with increasing the calcination. The electrode resistance of LSCF-SDC composites calcined at 1073K was dominated by $\mathrm{R}_{\mathrm{M}}$ and the cathode reaction processes were dominant by bulk diffusion of adsorbed of $\mathrm{O}^{2-}$ in the bulk LSCF phase. Dissociation of molecular adsorbed oxygen into atom adsorbed oxygen on cathode surface became the oxygen reduction reaction rate-determining steps when the LSCF precursors were calcined at $1473 \mathrm{~K}$ for $4 \mathrm{~h}$.

\section{Conclusions}

The oxygen reduction reaction mechanism in the porous LSCF-SDC nano-sized composite cathode is studied through a comparison with that in the porous LSCF-SDC micro-size composite cathode. The polar impedances of nano-sized LSCF-SDC cathodes are much lower than those of micro-sized LSCF-SDC cathodes. The area specific resistance of the LSCF-SDC composite cathodes is only $0.21 \Omega \cdot \mathrm{cm}^{2}$ at $873 \mathrm{~K}$ when the average particle size of LSCF is about $50 \mathrm{~nm}$ and that of the LSCF-SDC composite cathode is $2.1 \Omega \cdot \mathrm{cm}^{2}$ at $873 \mathrm{~K}$ when the particle size of LSCF is $1.2 \mu \mathrm{m}$. The polar resistance of LSCF-SDC composite cathodes calcined at $1073 \mathrm{~K}$ was dominated by medium frequency processes which show a relatively weak $p\left(O_{2}\right)$ 
dependence $(n=0.26)$ at $873 \mathrm{~K}$ and the bulk diffusion of adsorbed of $\mathrm{O}^{2-}$ in the bulk LSCF phase is the dominant step. The impedance spectra of the composite cathodes calcined to $1473 \mathrm{~K}$ showed more strongly dependent on $p\left(O_{2}\right)(n=0.42)$. Dissociation of molecular adsorbed oxygen into atom adsorbed oxygen on cathode surface is the oxygen reduction reaction rate-determining step.

\section{Acknowledgements}

The authors gratefully acknowledge the financial support from the National Science Foundation of China under contract No. 51402104. 


\section{References}

[1] Brian C.H. Steele, Angelika Heinzel, Nature 414(2001) 345-352.

[2] E. Perry, M.J. Sever, S.A. Barnett, Solid State Ionics 148(2002)27-34.

[3] F. Zhao Z.Y. Wang, M.F. Liu, L. Zhang, C.R. Xia, F.L. Chen, Journal of Power Sources 185(2009)13-18.

[4] B.C.H. Steele. Solid State Ionics, 129 (2000) 95-110.

[5] Y.D. Zhen, A.I.Y. Tok, S.P. Jiang, F.Y.C. Boey. Journal of Power Sources, 178 (2008) 69-74.

[6] S.B. Adler, Soid State Ionics, 111(1998)125-134.

[7] A. TarancÓn, J. Peña-Martínez, D. Marrero-López, A.Morata,J.C. Ruiz-Morales, P. Núñez, Solid State Ionics, 179(2008)2372-2378.

[8] Hanping Ding, Xingjian Xue, 35(2010)4316-4319.

[9] W. Yang, T. Hong, S. Li, Z.H. Ma, C.W. Sun, C.R. Xia, L.Q. Chen, ACS Applied Materials \& Interfaces, 5(2013)1143-1148.

[10] Wei Zhou, Ran Ran, Zongping Shao, Journal of Power Sources, 192(2009) 231-246.

[11] Y. Zhang, B. Yu, S. Lü, X. Meng, X. Zhao, Y. Ji, Y. Wang, C. Fu, X. Liu, X. Li, Y. Sui, J. Lang, J, Electrochimica Acta, 134(2014)107-115.

[12] Changrong Xia, William Rauch, Fanglin Chen, Meilin Liu, Solid State Ionics, 
149(2002)11-19.

[13] Zhiyi Jiang, Cahngrong Xia, Fanlin Chen, Electrochimica Acta 55 (2010)3595-3605 .

[14] San Ping Jiang, International Journal of Hydrogen Energy 37(2012)449-470.

[15] Trine Klemensø, Christodoulos Chatzichristodoulou, Jimmi Nielsen, Francesco Bozza, Karl Thydén, Ragnar Kiebach, Severine Ramousse, Solid State Ionics, 224 (2012) 21-31.

[16] F. Bidrawn, G. Kim, N. Aramrueang, J.M. Vohs, R.J. Gorte, Journal of Power Sources, 195 (2010) 720-728.

[17] You-Kee, Jung-Yeul Kim, Young-Ki Lee, Insoo Kim, Hee-Soo Moon, Jong-Wan Park, Craig P Jacobson, Steven J Visco, Journal of Power Sources, 115 (2003) 219-228.

[18] Xueqing Sha, Zhe Lü, Xiqiang Huang, Jipeng, Miao, Li Jia, Xianshuang Xin, Wenhui Su, Journal of alloys and compounds, 424(2006)315-321.

[19] Zhan Gao, Xingmin Liu, Bill Bergman, Zhe Zhao, Journal of Power Sources 196(2011)9195-9203.

[20] Da Han, Hao Wu, Junliang Li, Shaorong Wang, Zhongliang Zhan, Journal of Power Sources 246(2014)409-416.

[21] Teruhisa Horita, Katsuhiko Yamaji, Natsuko Sakai, Harui Yokokawa, André Weber, Ellen Ivers-Tiffée, Electrochimica Acta 46(2001)1837-1845. 
[22] C. Schwandt, W. Weppner, J. Electrochem. Soc. 144(1997) 3728-2738.

[23] Shizhong. Wang, Yi Jiang, Yahong Zhang, Jingwang Yan, Wenzhao Li, Solid State Ionics, 133-115 (1998) 291-303.

[24] S.B. Adler, solid state ionics, 111 (1998) 125-134.

[25] F. Bidrawn, R. Küngas, J. M. Vohs, R.J. GORT, Journal of Electrochemical Society, 158(2011)B514-B525.

[26] Xingyan Xu, Zhiyi Jiang, Xing Fan, Changrong Xia, Solid State Ionics, 177 (2006) 2113-2117. 
Fig.1 SEM cross-sectional morphology of the tri-layer structures of porous $\mid$ dense $\mid$ porous SDC at $1723 \mathrm{~K}$ for 4 hours

Fig.2 the XRD pattern for LSCF-SDC composite cathode at 1073K for 4 hours

Fig.3 SEM cross-sectional images of the LSCF-SDC composite cathodes sintered at (a) 1073K,

(b)1173K, (c)1273K, (d)1373K, (e)1473K.

Fig.4 A impedance spectrum of a LSCF-SDC cathode symmetric cell, which was caclined to $1073 \mathrm{~K}$, measured at $873 \mathrm{~K}$ in air atmosphere

Fig.5 Impedance spectra measured at $773 \mathrm{~K}$ for LSCF-SDC composites cathode sintered at different temperature

Fig.6 AC impedance spectra of LSCF-SDC composite cathodes calcined at (a)1073K, (b)1173K, (c)1273K, (d)1373K, (e)1473K under different oxygen partial pressure.

Fig.7 The impedance spectrum of the LSCF-SDC composite cathode (calined at 1073K) at 0.01 atm $p\left(\mathrm{O}_{2}\right)$ and $773 \mathrm{~K}$. An equivalent circuit $\left(\mathrm{R}_{\mathrm{H}} \mathrm{Q}_{\mathrm{H}}\right)\left(\mathrm{R}_{\mathrm{M}} \mathrm{Q}_{\mathrm{M}}\right)\left(\mathrm{R}_{\mathrm{L}} \mathrm{Q}_{\mathrm{L}}\right)$ was inserted in the figure.

Fig.8 The high frequency resistance $\left(\mathrm{R}_{\mathrm{H}}\right)$, the medium frequency resistance $\left(\mathrm{R}_{\mathrm{M}}\right)$ and the low frequency resistance $\left(\mathrm{R}_{\mathrm{L}}\right)$ of the LSCF-SDC composite cathodes measured at $873 \mathrm{~K}$. The ratio of $R_{H}, R_{M}$, and $R_{L}$ to the total cathode resistance $\left(R_{T}\right)$ are also shown.

Table 1 Dependence $(n)$ of electrode resistance in different frequency range on oxygen partial pressures 


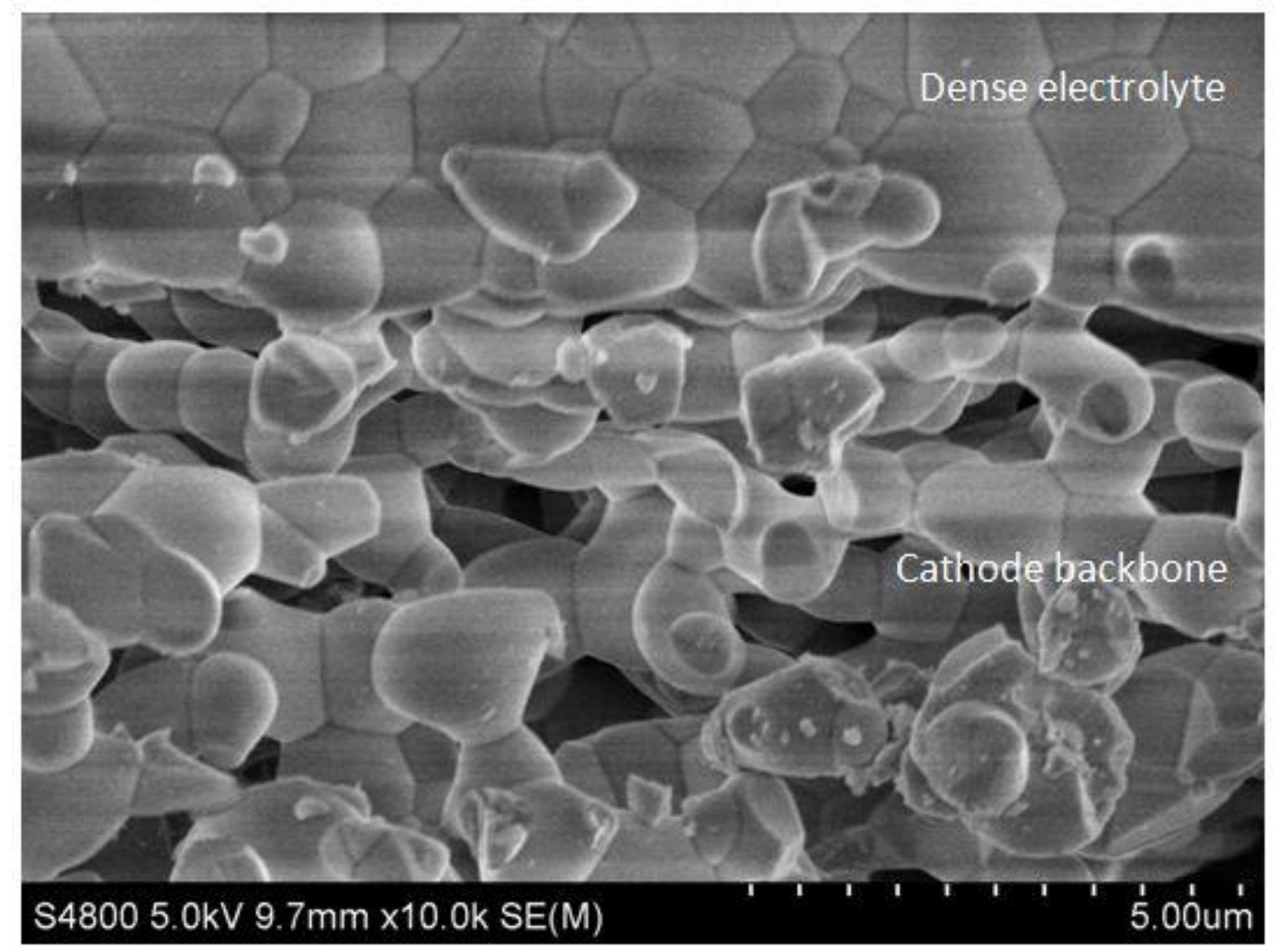




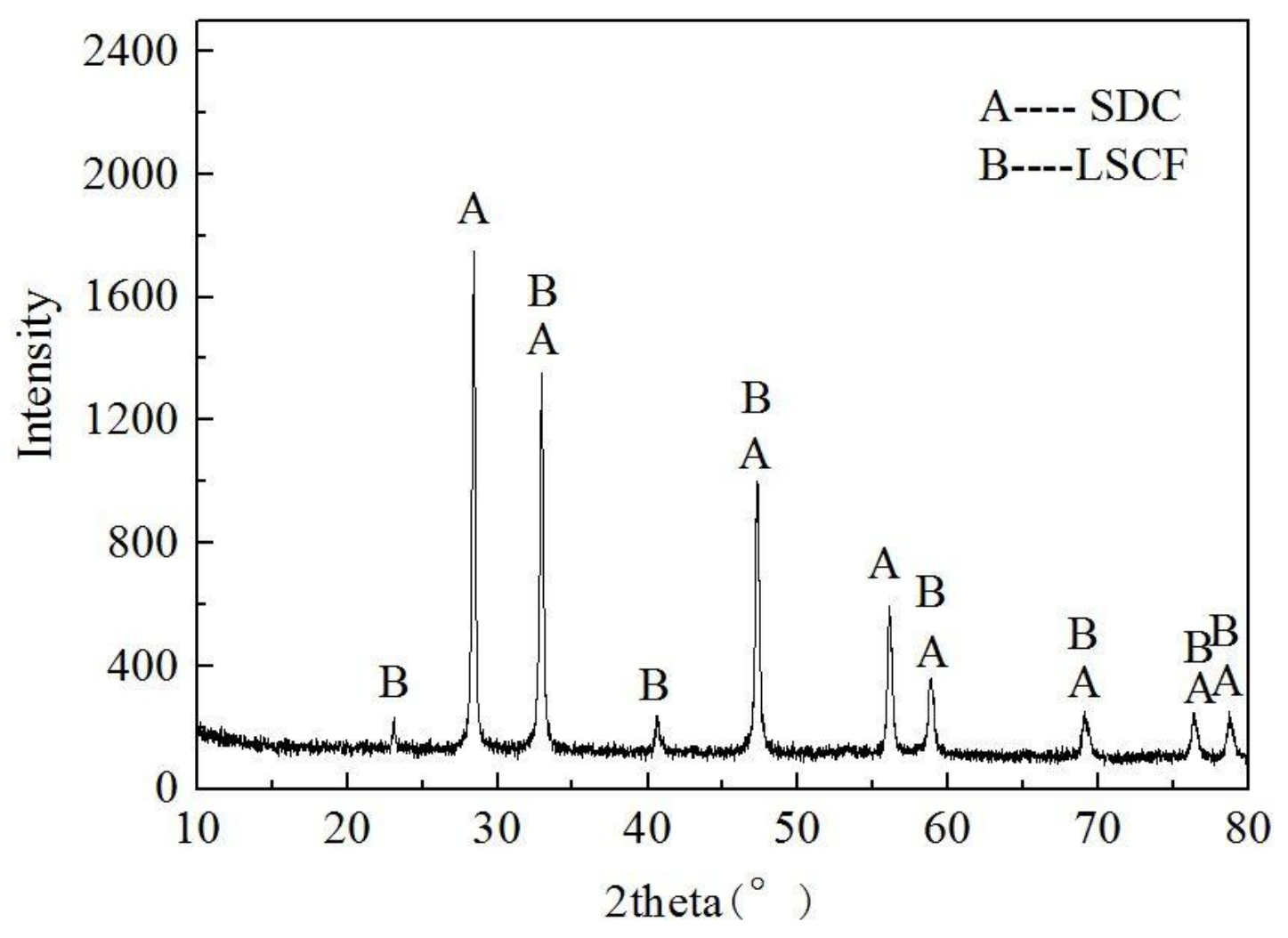




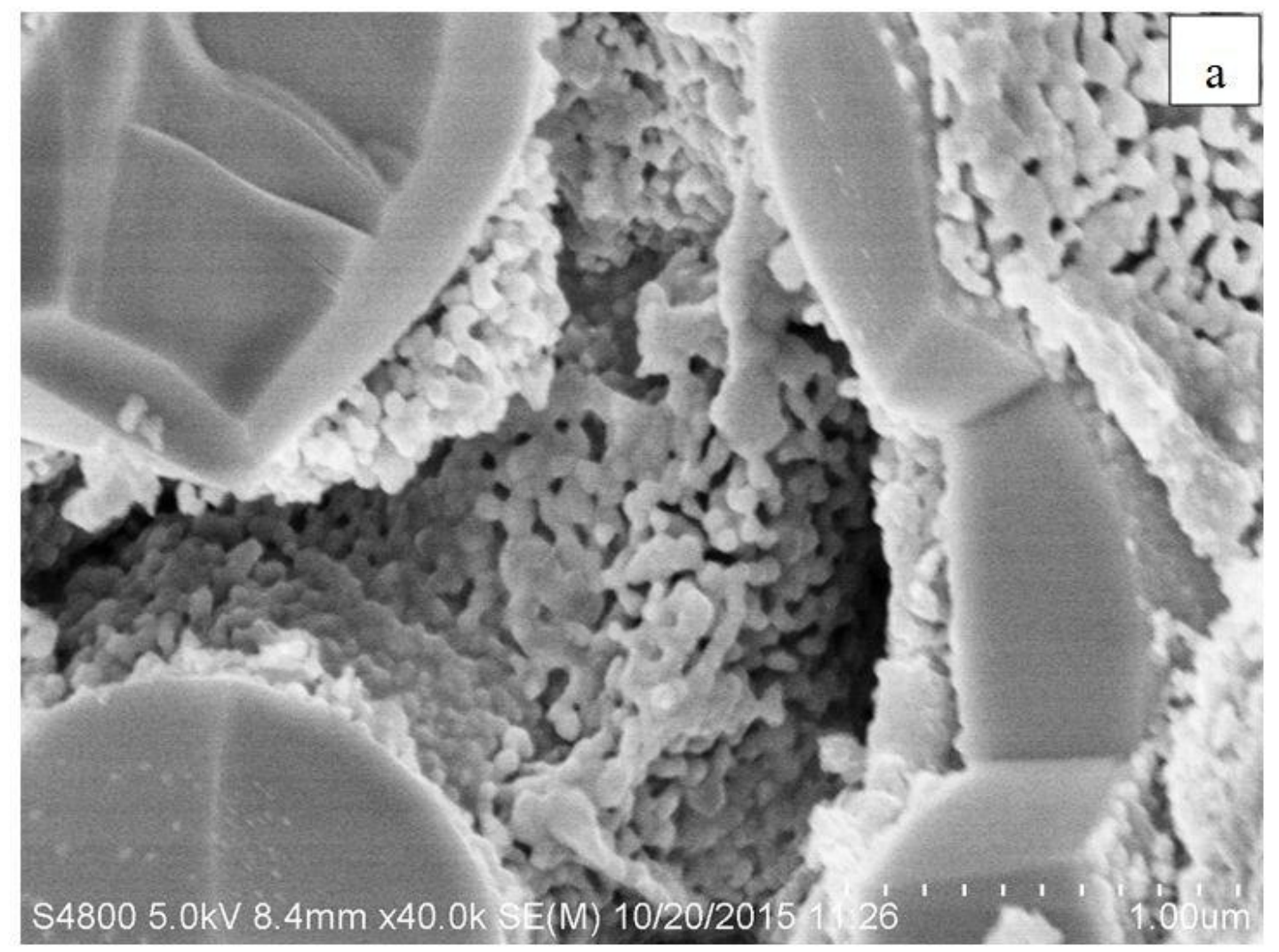




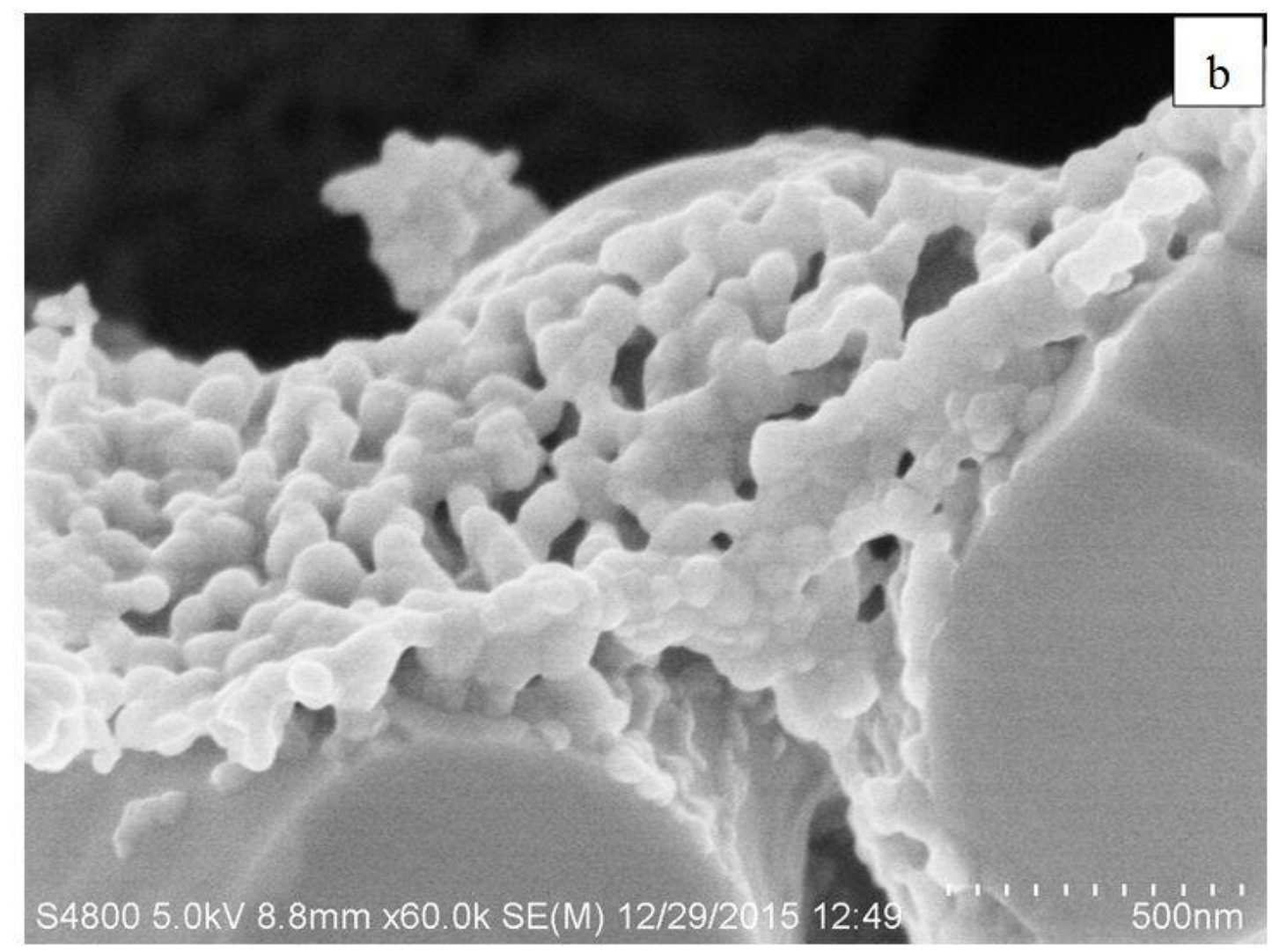




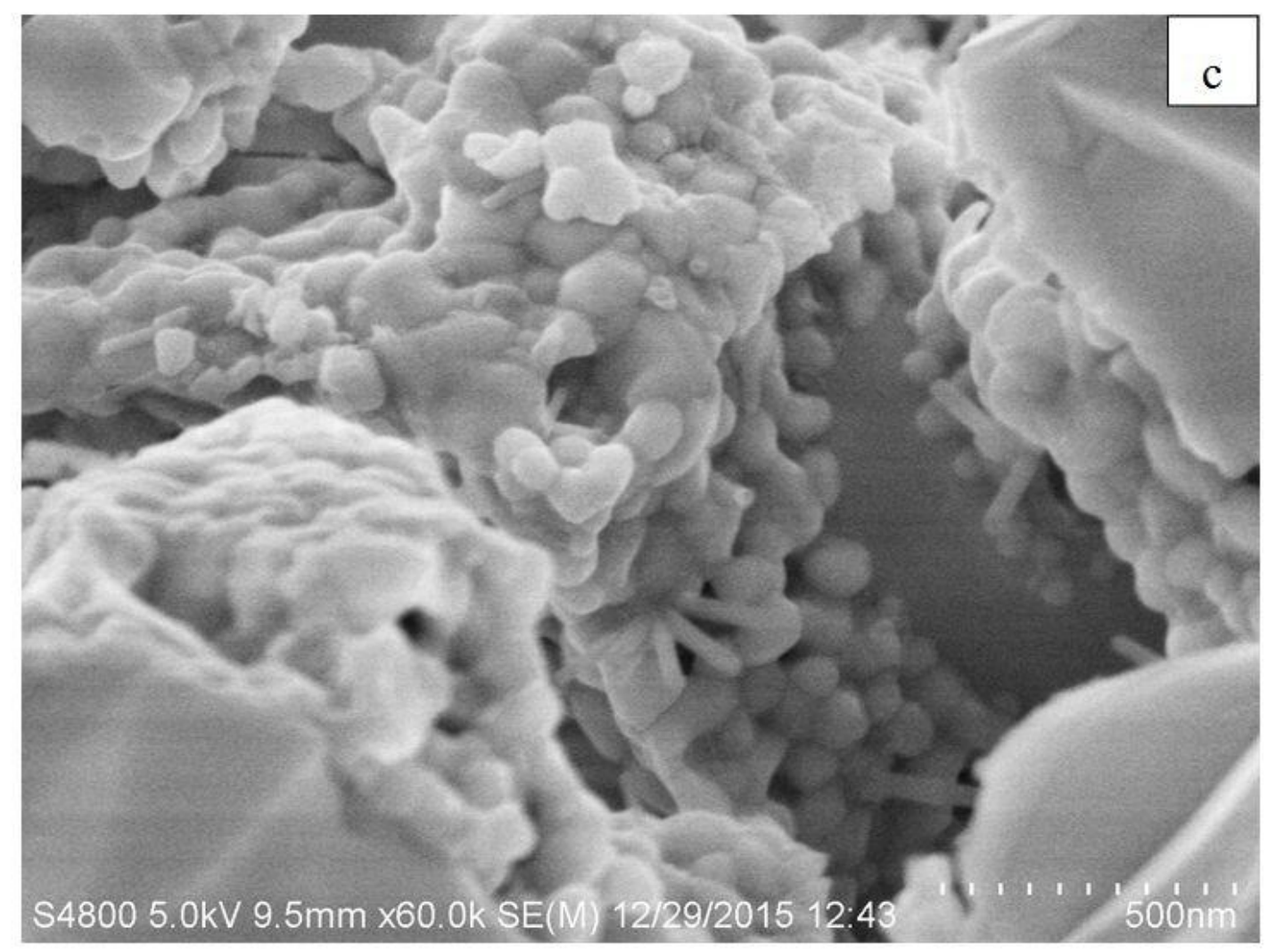




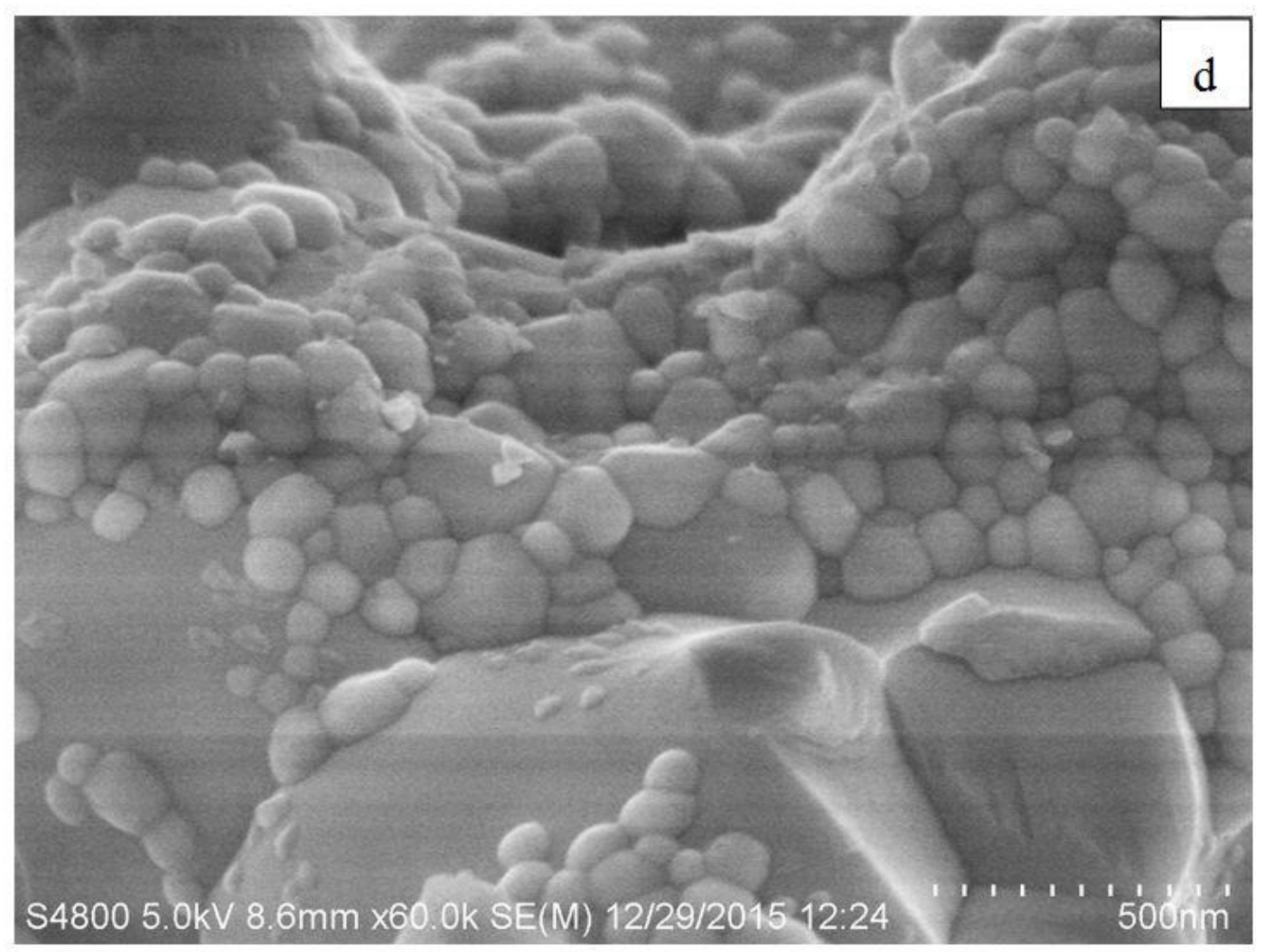




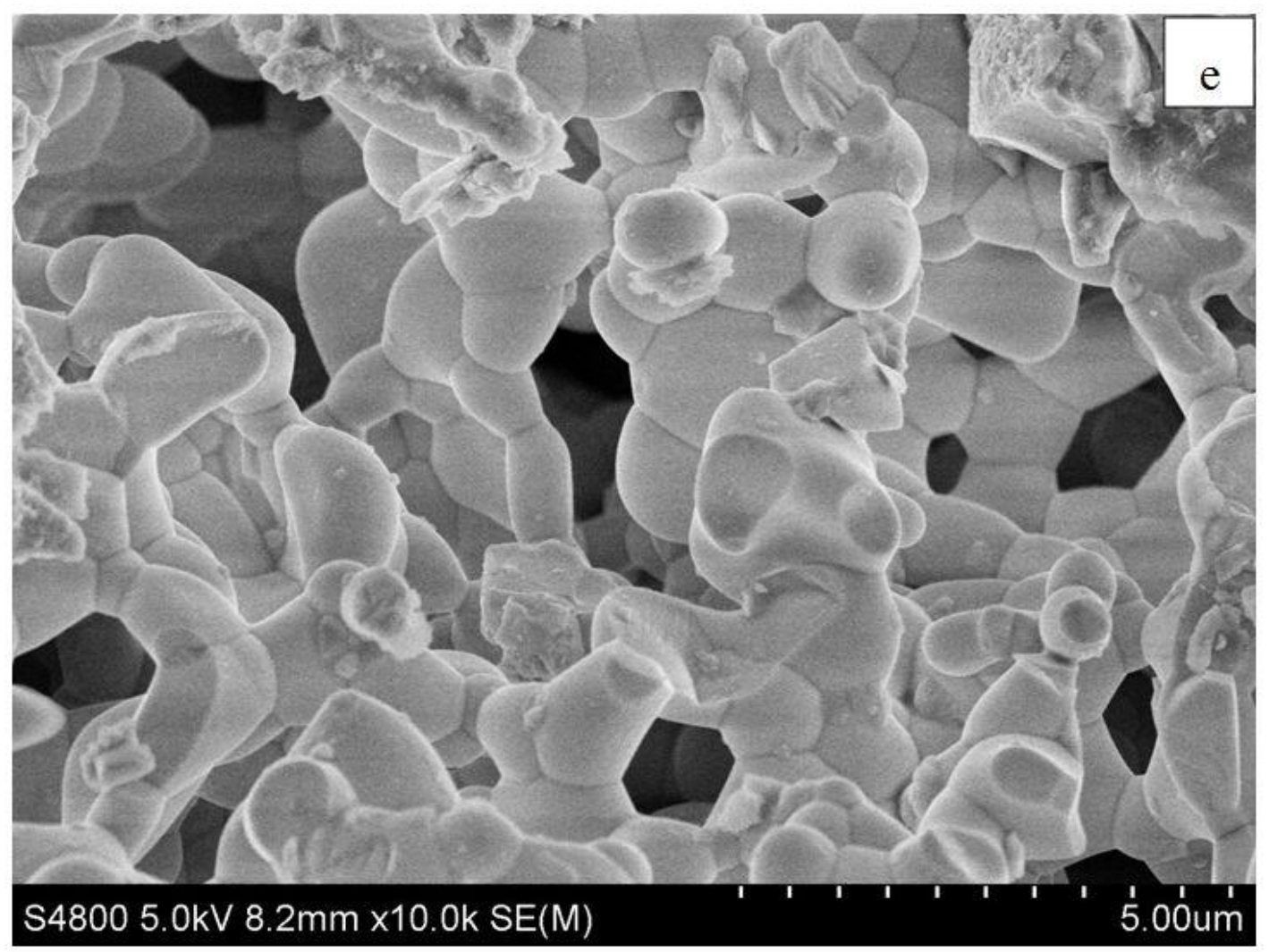




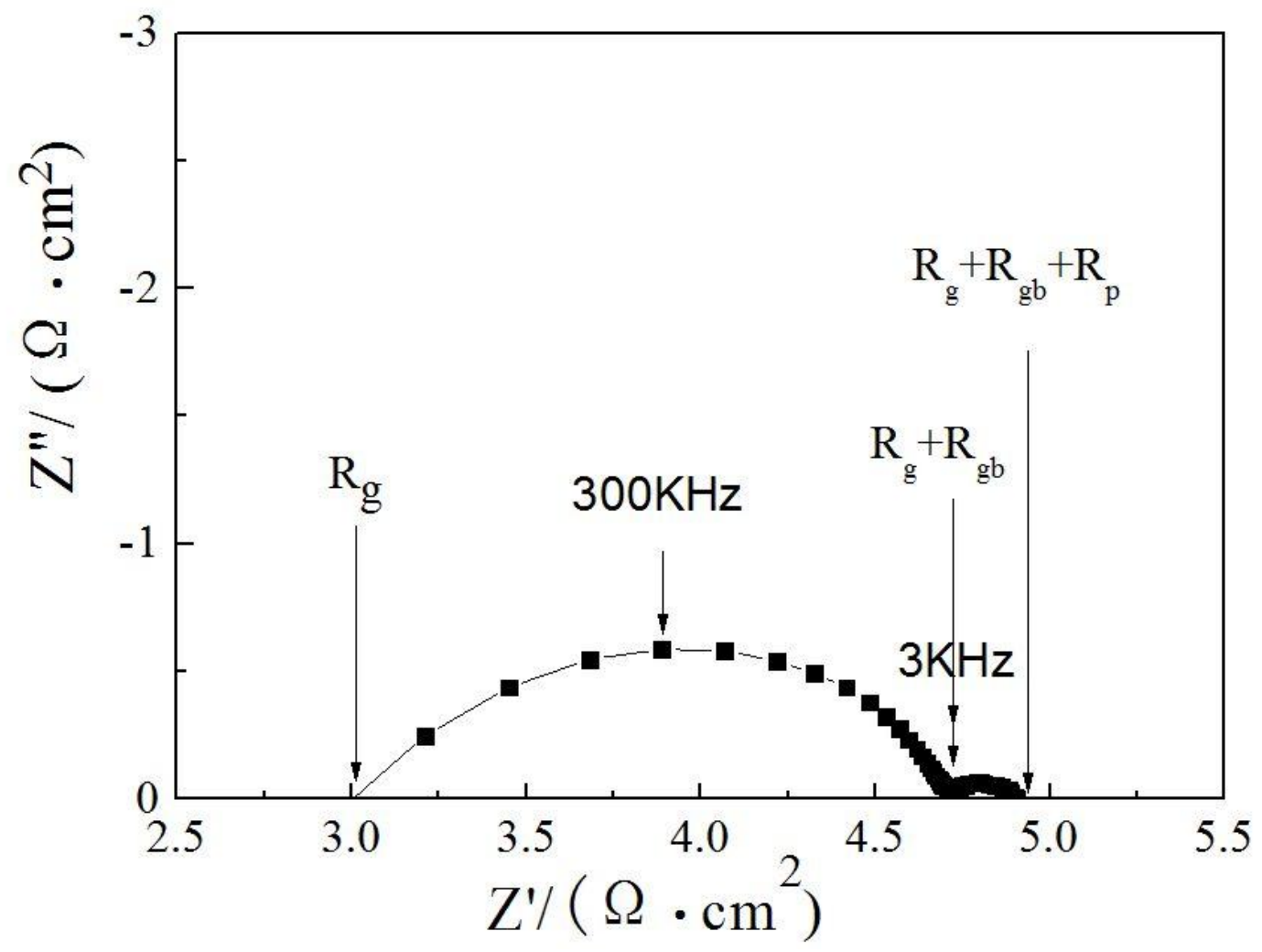




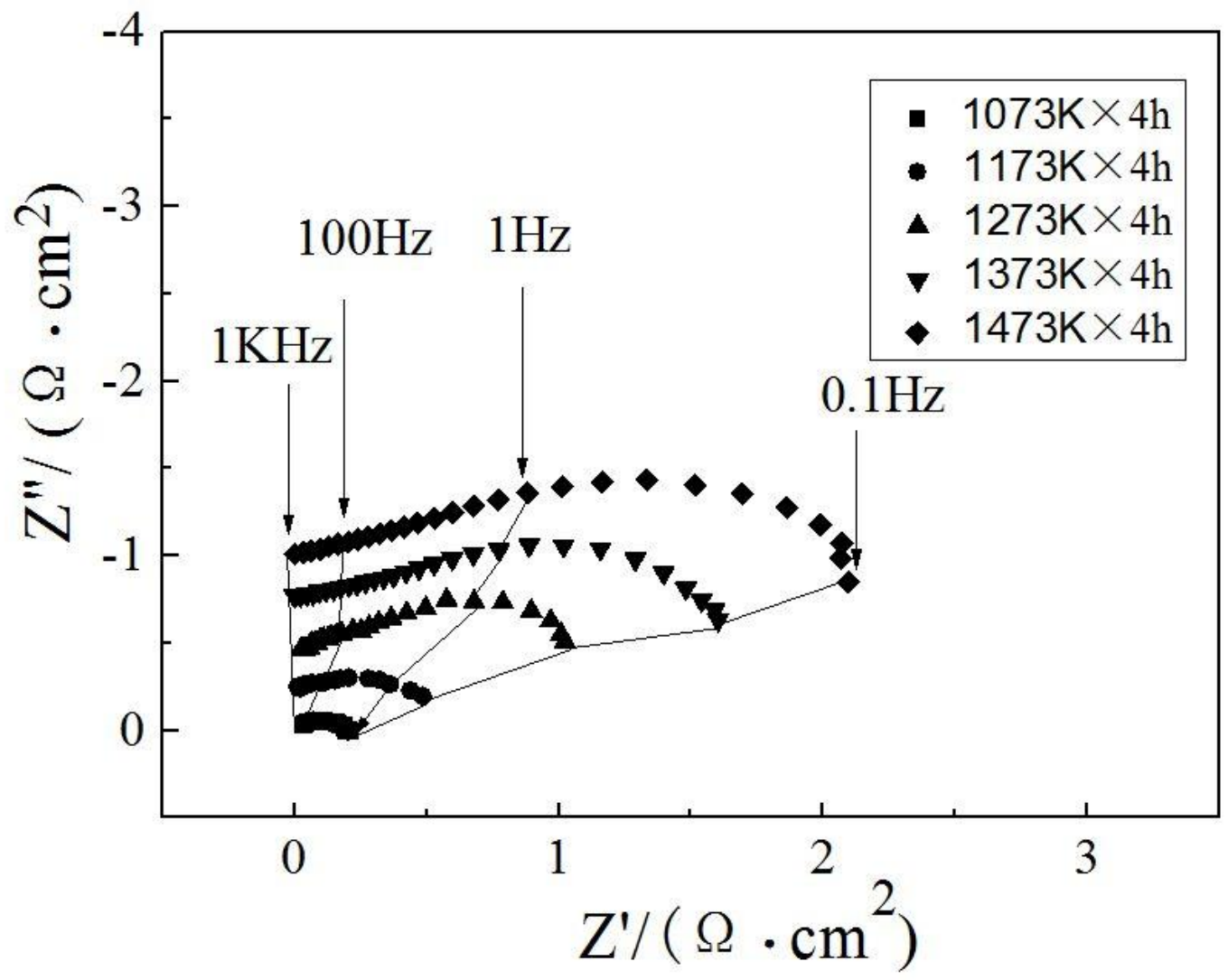




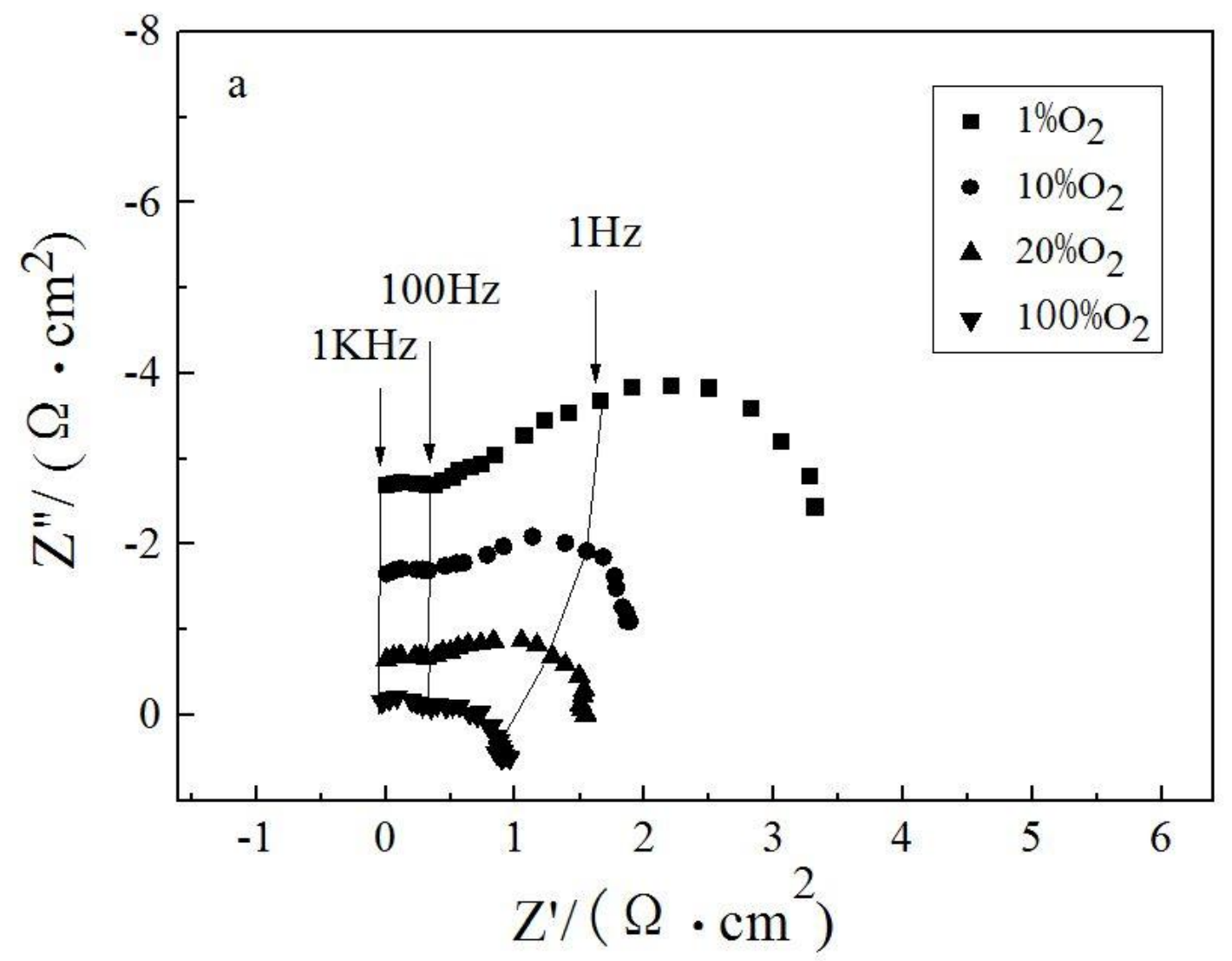




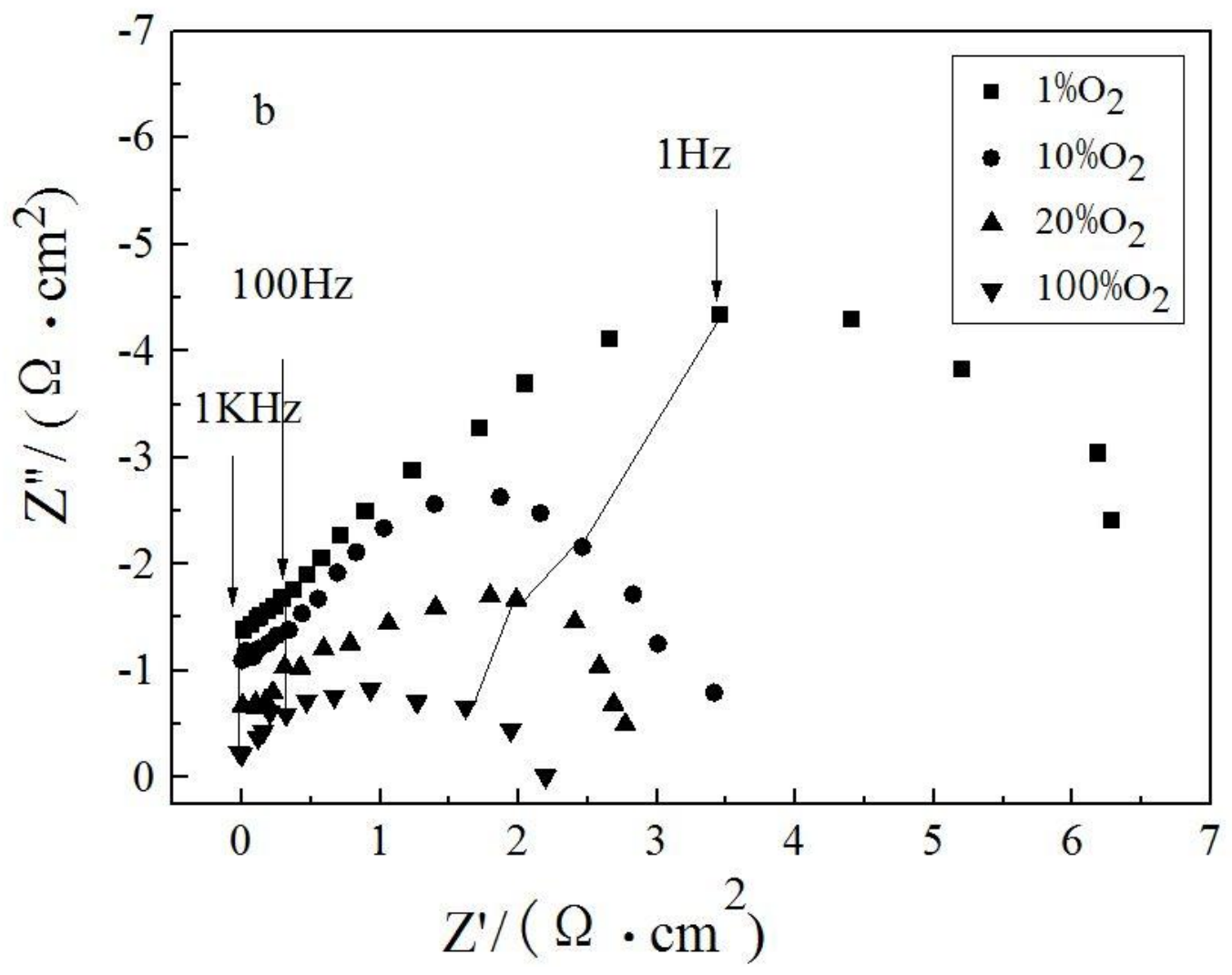




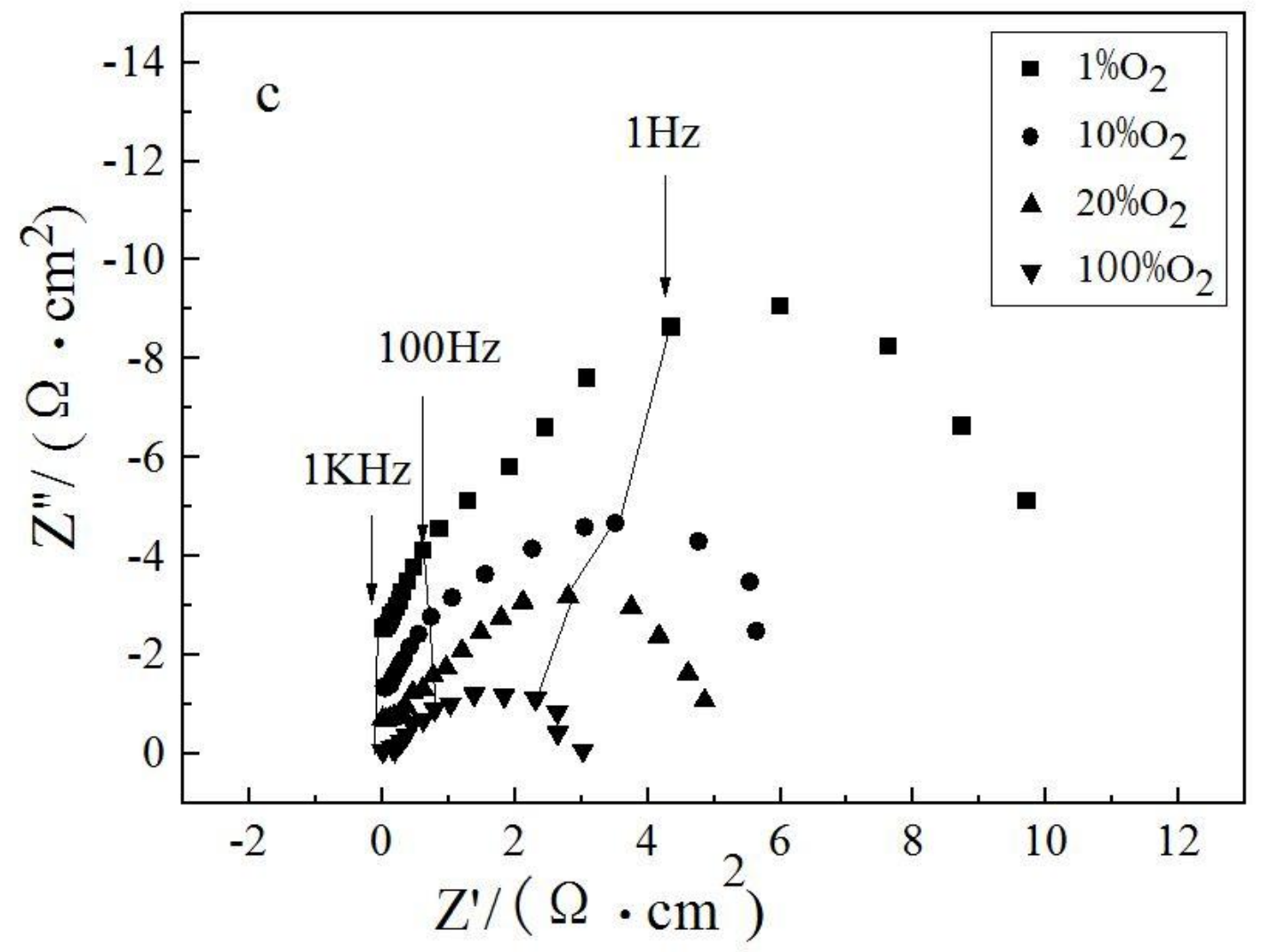




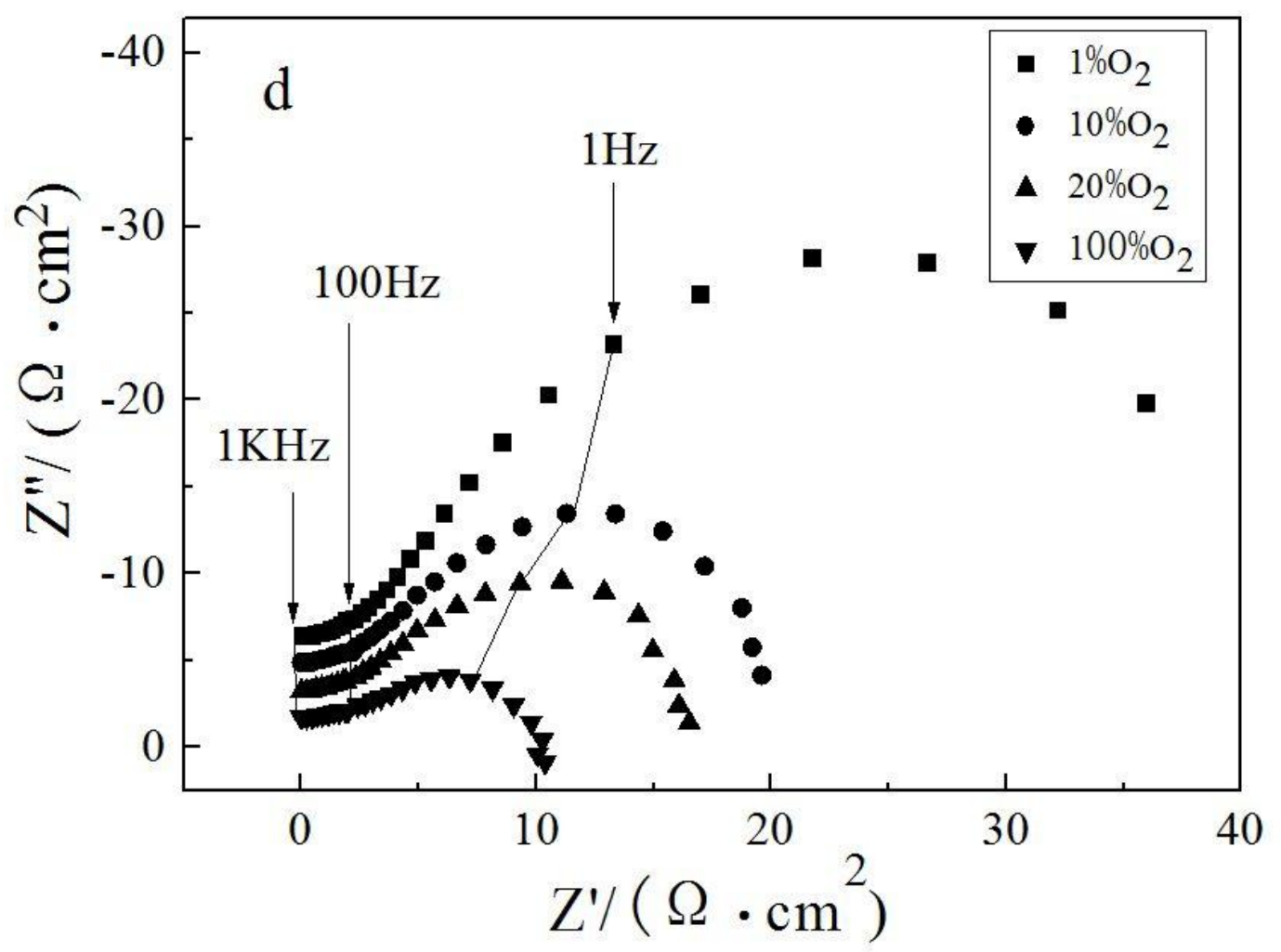




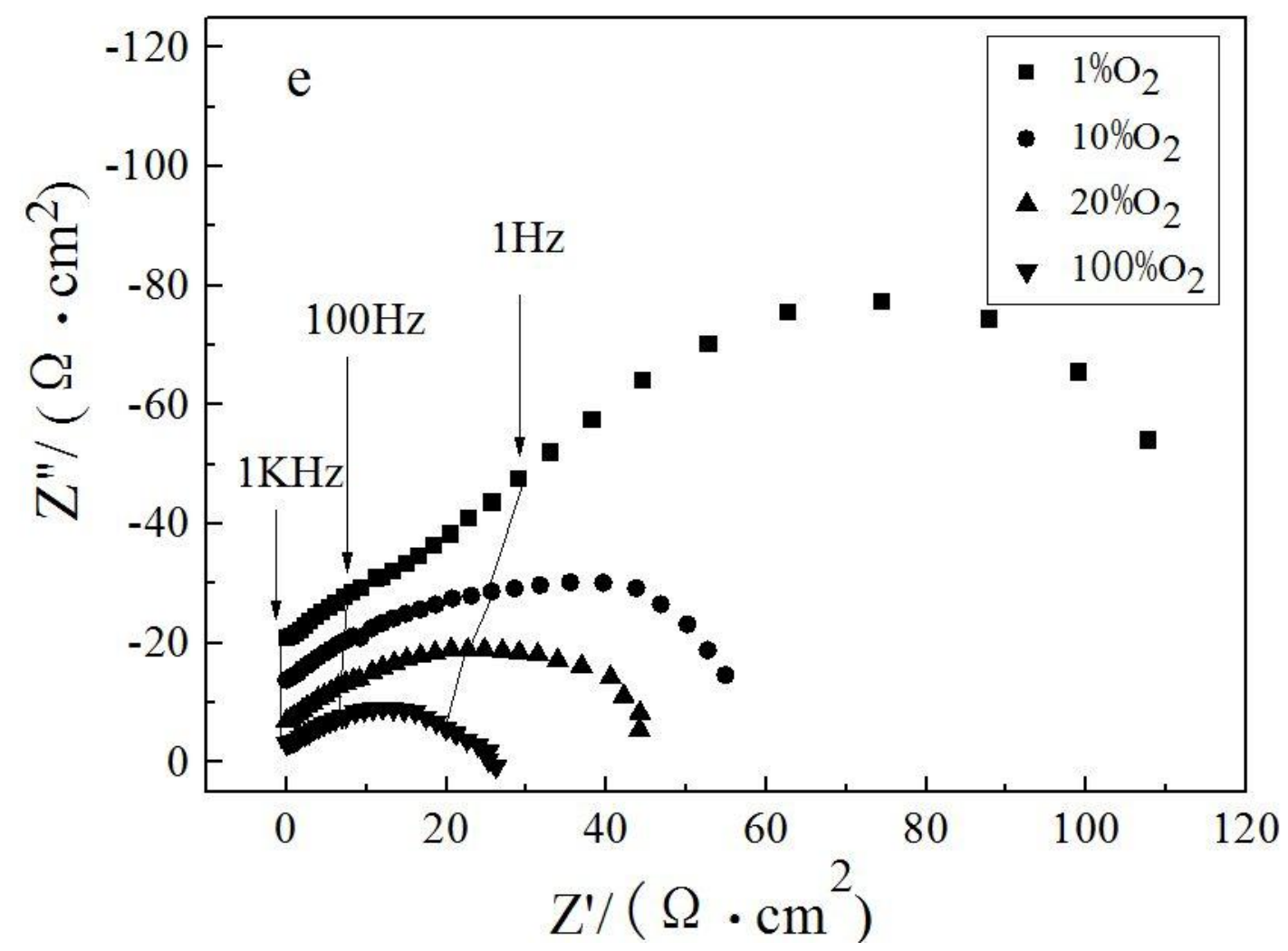




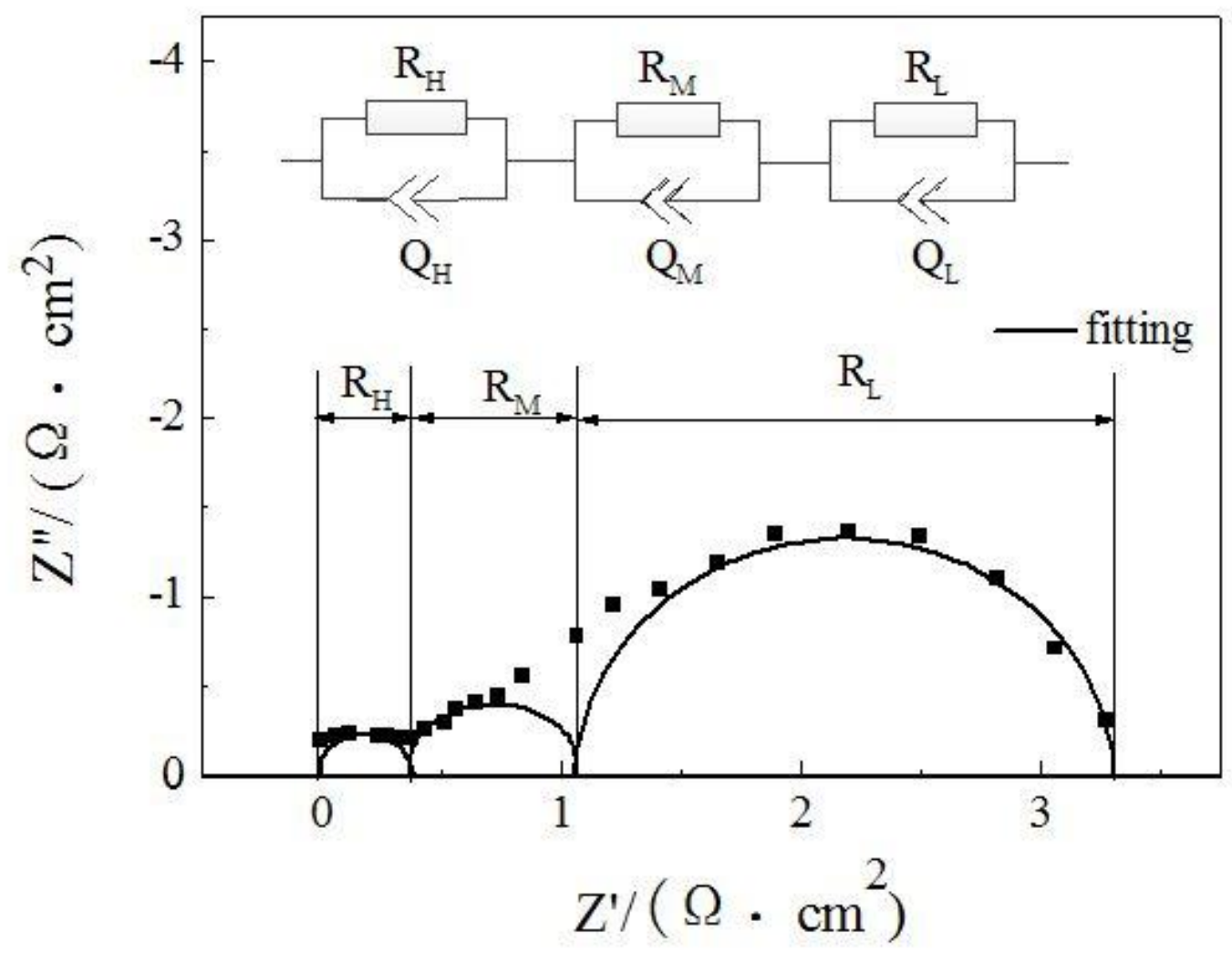




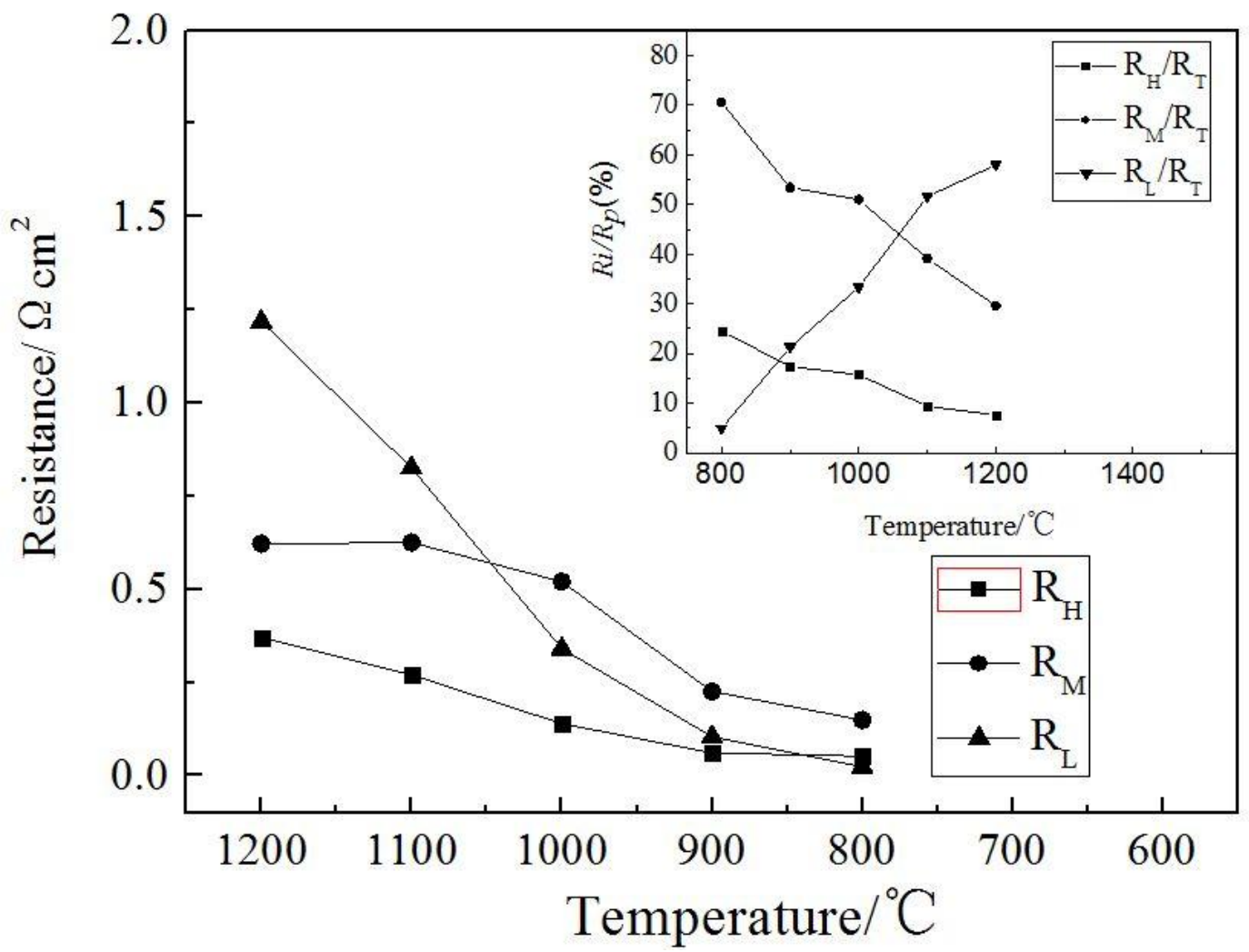


Table 1 Dependence $(n)$ of electrode resistance in different frequency range on oxygen partial pressures

\begin{tabular}{ccccc}
\hline $\begin{array}{c}\text { Calcination } \\
\text { temperature }\end{array}$ & $R_{H}$ & $R_{M}$ & $R_{L}$ & $R_{p}$ \\
\cline { 2 - 5 } $800^{\circ} \mathrm{C}$ & 0.01 & 0.25 & 0.55 & 0.26 \\
\hline $900^{\circ} \mathrm{C}$ & 0.05 & 0.29 & 0.47 & 0.28 \\
\hline $1000^{\circ} \mathrm{C}$ & 0.05 & 0.27 & 0.48 & 0.31 \\
\hline $1100^{\circ} \mathrm{C}$ & 0.03 & 0.23 & 0.55 & 0.37 \\
\hline $1200^{\circ} \mathrm{C}$ & 0.06 & 0.24 & 0.53 & 0.42 \\
\hline
\end{tabular}

